\title{
Predictive Factors of Surgery in Peptic Stenosis of the Bullb
}

\author{
Mohamed Ben Mabrouk1, Aida Ben Slama Trabelsi², Mehdi Ksiaa², Waad Farhat', \\ Ali Jmaa², Ali Ben Ali ${ }^{1}$ \\ ${ }^{1}$ Department of Digestive Surgery, Sahloul Hospital, Sousse, Tunisia \\ ${ }^{2}$ Department of Gastroenterology, Sahloul Hospital, Sousse, Tunisia \\ Email: mohamed.benmabrouk@rns.tn
}

Received 15 May 2015; accepted 11 September 2015; published 14 September 2015

Copyright (C) 2015 by authors and Scientific Research Publishing Inc.

This work is licensed under the Creative Commons Attribution International License (CC BY). http://creativecommons.org/licenses/by/4.0/

(c) (i) Open Access

\section{Abstract}

The bulb ulcer stenosis, becoming exceptional in developed countries, remains frequent in our country despite the use of the antisecretory. The purpose of our study was to study epidemiological, diagnostic, and evolutionary complication particularities, and to find potential predictive factors of resistance of ulcer stenosis of the bulb to the pump inhibitors Proton through a recent series. This is a retrospective and descriptive study involving 105 patients, treated for ulcer stenosis of the bulb between January 2007 and December 2012. All our patients had received inhibitors of Proton pump, parenterally for 7 days. They were divided into 2 groups according to their response to treatment: the first group (G1) was sensitive and the second (G2) was resistant. All patients of the G2 were operated. We had compared the two groups. There was no statistically significant difference concerning age, sex, blood group and smoking between the two groups. In univariate study, the age of the epigastralgies was greater than or equal to 9 years; the clapotage fasting, dilation and gastric atony, objectified by the oesogastroduodenal transit were significantly associated with the failure of medical treatment. Only gastric atony and seniority of the disease over 9 years were independent risk factors of resistance to the Proton pump inhibitors in multivariate study.

\section{Keywords}

Bulbar Ulcer, Stenosis, Surgery, Proton Pump Inhibitors

\section{Introduction}

Peptic ulcer disease is the most common cause of benign gastric outlet obstruction (GOO). After the association

How to cite this paper: Mabrouk, M.B., Trabelsi, A.B.S., Ksiaa, M., Farhat, W., Jmaa, A. and Ali, A.B. (2015) Predictive Factors of Surgery in Peptic Stenosis of the Bulb. Open Journal of Gastroenterology, 5, 129-133.

http://dx.doi.org/10.4236/ojgas.2015.59021 
between Helicobacter pylori and peptic ulcer was recognized, less than $5 \%$ patients with complicated duodenal ulcer disease have developed this complication. Patients with ulcer-related GOO often have a long history of symptoms due to ulcer disease.

Stenosis is the 3rdbulbar ulcer complication after hemorrhage and perforation, which usually occurs after a long evolutional, non- or under-treated disease. It is still common, in our country, despite the development of potent anti-ulcer drugs. Several studies have investigated the place of triple therapy and endoscopic treatment in the management of peptic stenosis of the bulb. Usually surgery is indicated in case of failure of other treatment, but no study has attempted to identify predictive factors of resistance to Proton pump inhibitors, which may indicate the surgical treatment of first-line.

The aim of our study was to study epidemiological, diagnostic, and evolutionary complication particularities, and to find potential predictors of resistance of ulcer stenosis of the bulb (USB) to PPIs, through a recent series.

\section{Materials and Methods}

\subsection{Type of the Study}

It is a retrospective, analytical, comparative study including all patients who have been explored for bulb ulcer stenosis in gastroenterology and digestive surgery department of Sahloul Hospital in Sousse during the period from January 2007 and December 2012.

\subsection{Criteria for Inclusion}

We include all patients that present a bulb ulcer stenosis, diagnosed on clinical (late postprandial vomiting, clapotage on an empty stomach, epigastic pain), endoscopic criteria (gastric stasis, stenosis of the bulb, deformed bulb) and radiological (gastric dilatation, gastric aperistaltisme, stasis). All patients were treated with inhibitors of Proton pump, parenterally for 7 days. According to the effectiveness of Proton pump inhibitors, our patients were divided into two groups: the first group (G1) has evolved under medical treatment, and the second (G2) was resistant. All patients of the G2 were operated. We had compared the two groups regarding age, sex, blood group $\mathrm{O}$, tobacco, duration of disease, clapotage fasting, gastric atony and gastric dilatation.

\subsection{Statistical Analysis and Expression of Results}

We used a SPSS 19.0 software, a khi2 test was performed to realize the univariate analysis of predictors of resistance to medical treatment. All variables with degrees of significance less than $5 \%$ il the univariate analysis were included in the multivariate analysis.

\section{Results}

We collected 105 patients meet the criteria for inclusion. The average age of our patients was 49 years (18 - 97). It was of 89 men and 16 women. The predominant blood group was the Group O (47.5\%). The notion of smoking was found in $62 \%$ of our patients with an average consumption of 30 packages year (3 - 100). In 55\% of patients, a history of non-complicated ulcer disease diagnosed and treated, was found, with an average age of 8.6 years. The clinical presentation was dominated by epigastric pain (100\%), vomiting (93\%) and weight loss (70\%). The clapotage fasting was found in $50 \%$ of cases. A state of malnutrition was observed in $10 \%$ of patients. The average age of epigastric pain was 8.68 years in all patients. Biologically, ionic disturbances were found in $1 / 3$ of patients, biological renal failure $12 \%$ cases, and anemia in $41 \%$ of cases. Oesogastro-duodenal fibroscopy (OGDF), had supported expandable bulbar ulcer 93.3\% of the time. The high digestive opacification had highlighted gastric dilatation in $40 \%$ of cases, a gastric aperistaltisme in $25 \%$ of cases, the absence of duodenal portion of the barium in $6.25 \%$ cases, and the presence of stasis in $93 \%$ of cases.

All our patients were put under IPP double dose intravenously. Twenty-nine patients have been improved under IPP with a clinical and biological improvement, and 76 patients were resistant to these drugs.

76 (72.38\%) patients were operated after failure of the medical treatment with Proton pump inhibitors. Surgical treatment consisted of a truncal vagotomy associated with antrectomy in $62.3 \%$ and gastroenterostomy in $37.1 \%$ of the cases. Histological examination, if antrectomy, concluded a Helicobacter pylori gastritis in 55\% of cases. Post operative complications were occurred in $9.8 \%$ of cases. $8.2 \%$ of patients have kept postoperative functional sequelae with a mean follow-up of 43 months (6 - 91). 
In the comparative study, there was no statistically significant difference concerning age, sex, blood group and smoking between the two groups. The average duration of epigastric pain was 5 years in the G1 and G2 9.32 years; to identify a cut-off value discriminating our patients, we have established a ROC (Receiver Operating Characteristics) curve, after checking that the area under the curve is significantly $>0.5$, we have chosen as the threshold, the value of the variable that corresponds to the best couple sensitivity-specificity. Thus, a positive correlation was found between a duration of disease $>$ or equal to 9 years and resistance to PPIs $(p=0.005)$.

The clapotage fasting was significantly more frequent in the G2 $(57.37 \%)$ than in G1 $(26.31 \%)$ with a p $=$ 0.018. The dilation and the gastric atony, objectified by the oesogastroduodenal (OGDT) transit, were more frequently found in the G2 as the G1 (respectively $67.21 \%$ vs. $26.31 \%$ and $26.23 \%$ vs. $0 \%$ ) with a significant difference $(\mathrm{p}=0.031$ and $\mathrm{p}=0.006$, respectively) (Table 1$)$.

Among the risk factors found in the univariate study, only gastric atony and duration of the disease over 9 years, were independent risk factors of resistance to the PPI in multivariate study (Table 2).

\section{Discussion}

Stenosis is the third complication of bulbar ulcer after hemorrhage and perforation [1] [2]. It usually occurs after a long evolution, non- or under-treated disease. The average duration of the disease varies between 6.4 and 14.5 years according to the series. It was 8.68 years in our series. The SUB complicated $7 \%-15 \%$ of the whole of the bulbar ulcer in Western literature [3]. In the series North African, its frequency varies around 20\% [4].

It can occur at any age, but particularly among young. The average age of patients with USB varies between 35 and 50 years according to the series. A male predominance in our series, was noted in the literature [5] [6].

The clinical picture is dominated by the late postprandial vomiting and epigastric pain [6]. The review may highlight a weight loss, dehydration and a clapotage on an empty stomach. Table evolves in two phases, sthenique with violent postprandial pain relieved by vomiting, then asthenique with decrease or disappearance pain and vomiting, becoming more widely spaced but more abundant and containing ingested food sometimes several days previously. The frequency of infection with Helicobacter pylori is high in our series (55\%) as well as in the European series [7] compared to American series [8] [9]. Unlike our study where PPI therapy had allowed the treatment of stenosis in $23.75 \%$ of cases, approximately $90 \%$ of the Western USB were treated successfully by a triple therapy [10] [11]. This fact is probably linked to the later discovery of stenosis in our patients, at a stage where the inflammatory component, target PPIs, is important [12]. In addition, the better observance of the antisecretory treatment in the West, thanks in part to their better availability with their cheaper cost, reduces the number of ulcer flare-ups that play an important role in the genesis of the irreversible fibrous stenosis [13]. These findings are the limits of our study in the selection of patients, in addition to the mono-centric caracter of our study.

Table 1. Predictors of surgery in univariate study.

\begin{tabular}{|c|c|c|c|c|}
\hline & Group $1 \mathrm{~N}=29$ & Group $2 \mathrm{~N}=76$ & $\mathrm{p}$ & $95 \%$ CI \\
\hline Age & 44 years & 48 years & NS & \\
\hline Sex & $24 \mathrm{H} / 5 \mathrm{~F}$ & $64 \mathrm{H} / 12 \mathrm{~F}$ & NS & \\
\hline Blood group O & $48 \%$ & $46 \%$ & NS & \\
\hline Tobacco & $60.6 \%$ & 63.2 & NS & \\
\hline Duration of disease & 5 years & 9.3 years & 0.005 & {$[2.3-42.3]$} \\
\hline Clapotage fasting & $26.3 \%$ & $57.3 \%$ & 0.018 & {$[1.10-7.90]$} \\
\hline Gastric atony & $0 \%$ & $26.2 \%$ & 0.03 & [0.38 - 0.88] \\
\hline Gastric dilatation & $26.3 \%$ & $67.2 \%$ & 0.006 & [1.61 - 15.31] \\
\hline
\end{tabular}

Table 2. Independent risk factors of surgery in multivariate study.

\begin{tabular}{cccc}
\hline & $95 \%$ CI & Adjusted OR & p \\
\hline Duration of disease & {$[1.63-18.72]$} & 5.53 & 0.006 \\
Gastric atony & {$[0.77-0.97]$} & 0.86 & 0.015 \\
\hline
\end{tabular}


The literature review found no analytical study aimed at identifying the factors of resistance of the USB to the IPP. However, some factors, such as smoking, found in $47 \%$ - $56 \%$ of ulcerative, and blood group O, pre-dominant in the ulcerative, were associated with a higher frequency of occurrence of complications [14] including the stenosis. These factors were not associated with a resistance of the USB to the IPP in our series. The clapotage fasting, defined by the fact that depression sudden epigastrium, carried out $12 \mathrm{~h}$ after the meal, trained a characteristic sound, testifying to the presence of a liquid of gastric stasis, found that in the case of tight stenosis. The correlation of this physical sign with resistance to PPIs may be linked to the generally tighter character of the sclerotic USB over the inflammatory USB.

In contrast, ionic disturbances are not correlated to the severity of the SUB. Thus, their similar frequency in both groups was expected.

The USB evolves in 3 phases: a phase hyperkinetic (characterized by an increased stomach contractility), followed by a phase hypokinetique (characterized by a failure of gastric emptying and the beginning of dilatation of the stomach) and a phase of sluggish (characterized by an absence of gastric contractions and very important dilation of the stomach). The correlation of dilation and gastric atony, objectified by high digestive opacification, resistance in the IPP is explained by the character old and often fibrous, these strictures [15].

\section{Conclusion}

Most of our USB are resistant to PPIs. The evolution of the epigastralgies for more than nine years, and the gastric atony to the TOGD are predictors of resistance of the USB to the IPP. This complication prevention necessarily involves a wider use of triple therapy.

\section{References}

[1] Milosavljevic, T., Kostić-Milosavljević, M., Jovanović, I. and Krstić, M. (2011) Complications of Peptic Ulcer Disease. Digital Distribution, 29, 491-493. http://dx.doi.org/10.1159/000331517

[2] Vaira, D., Menegatti, M. and Miglioli, M. (1997) What Is the Role of Helicobacter Pylori in Complicated Ulcer Disease? Gastroenterology, 113, S78-S84. http://dx.doi.org/10.1016/S0016-5085(97)80017-0

[3] Ellis, H. (1987) Pyloric Stenosis Complicating Duodenal Ulceration. World Journal of Surgery, 11, 315-318.

[4] Fadil, A., Moumen, M., Bellakhdar, A. and El Fares, F. (1992) Pyloroduodenalstenosis of Ulcer Origin. Apropos of 260 Cases. Journal de Chirurgie (Paris), 129, 27-30.

[5] Ben Mahmoud, N., Hajji, L., Ghozzi, M., Elloumi, M., Siai, K. and Azzouz, M.M. (2010) Dilatation endoscopique des sténoses ulcéreuses bulbaires: rEsultats et facteurs prédictifs de son efficacité: Etude.de 45 cas. SNFGE, Abstract.

[6] Yenon, K., Koffi, E. and Kouassi, J.C. (1999) La sténose ulcéreuse pyloro-duodénale: Aspects diagnostiques et thérapeutiques. A propos de 38 cas. Médecine d'Afrique Noire, 46, 119-122.

[7] Mirodzhov, G.K., Kadyrov, D.M., Rashidov, F.K., Ishankulova, D.M., Shamsuddinov, Sh.N. and Bulbulov, K.B. (2004) Anti-Helicobacter Therapy for Duodenal Peptic Ulcer Complicated by Pyloroduodenal Stenosis. Kliniceskaia Meditsina (Moskva), 82, 51-54.

[8] Gibson, J.B., Behrman, S.W., Fabian, T.C. and Britt, L.G. (2000) Gastric Outlet Obstruction Resulting from Peptic Ulcer Disease Requiring Surgical Intervention Is Infrequently Associated with Helicobacter Pylori Infection. Journal of the American College of Surgeons, 191, 32-37. http://dx.doi.org/10.1016/S1072-7515(00)00298-2

[9] Zelickson, M.S., Bronder, C.M., Johnson, B.L., Camunas, J.A., Smith, D.E., Rawlinson, D., Von, S., Stone, H.H. and Taylor, S.M. (2011) Helicobacter Pylori Is Not the Predominant Etiology for Peptic Ulcers Requiring Operation. The American Surgeon, 77, 1054-1060.

[10] Brandimarte, G., Tursi, A., Di Cesare, L. and Gasbarrini, G. (1999) Antimicrobial Treatment for Peptic Stenosis: A Prospective Study. European Journal of Gastroenterology and Hepatology, 11, 731-734. http://dx.doi.org/10.1097/00042737-199907000-00009

[11] Taskin, V., Gurer, I., Ozyilkan, E., Sare, M. and Hilmioglu, F. (2000) Effect of Helicobacter Pylori Eradication on Peptic Ulcer Disease Complicated with Outlet Obstruction. Helicobacter, 5, 38-40. http://dx.doi.org/10.1046/j.1523-5378.2000.00005.x

[12] Shabbir, J., Durrani, S., Ridgway, P.F. and Mealy, K. (2006) Proton Pump Inhibition Is a Feasible Primary Alternative to Surgery and Balloon Dilatation in Adult Peptic Pyloric Stenosis (APS): Report of Six Consecutive Cases. Annals of the Royal College of Surgeons of England, 88, 174-175. http://dx.doi.org/10.1308/003588406x94959

[13] Jamieson, G.G. (2000) Current Status of Indications for Surgery in Peptic Ulcer Disease. World Journal of Surgery, 24, 256-258. http://dx.doi.org/10.1007/s002689910041 
[14] Marquez, M., Ducons, J.A., Lanas, A., Martinez, T. and Sainz, R. (1989) Prevalence of Peptic Ulcer in Smokers and Non Smokers in Aragon. Revista Española de las Enfermedades Del Aparato Digestivo, 75, 566-571.

[15] Menon, S. (2008) Benign Pyloro-Duodenal Stenosis. Gastrointestinal Endoscopy, 67, 578-579. http://dx.doi.org/10.1016/j.gie.2007.09.051 